\title{
UMA LINHA ABISSAL NO ESTADO DEMOCRÁTICO DE DIREITO: O DIREITO PENAL DO INIMIGO
}

Fernanda Otero Costa

nandaotero@gmail.com

\section{RESUMO}

O trabalho propõe uma análise do Direito Penal do Inimigo, tendo como pano de fundo a Teoria das Linhas Abissais desenvolvida pelo sociólogo português Boaventura de Sousa Santos. A partir do sistema funcionalista defendido por Günther Jakobs e da idéia de inimigo analisada sob um viés político, filosófico e normativo, pretende-se demonstrar, não obstante a presença recorrente de práticas características do Direito Penal do Inimigo no âmbito jurídico, a incompatibilidade do mesmo com o Estado Democrático de Direito ideal.

Palavras-chave: Direito Penal do Inimigo - Funcionalismo sistêmico - Linhas Abissais -

Estado Democrático de Direito.

\section{ABSTRACT}

This work proposes an analysis of the Enemy Criminal Law having as background the Abyssal Lines Theory developed by the Portuguese sociologist Boaventura de Sousa Santos. From the functionalist system defended by Günther Jakobs and the idea of enemy analyzed under a political, philosophical and normative bias it is intended to demonstrate, regardless the recurrent presence of the Enemy Criminal Law practices in the juridical ambit, its incompatibility with the ideal democratic rule-of-law state.

Keywords: Enemy Criminal Law, Systemic Functionalism, Abyssal Line, Democratic Ruleof-Law State.

\section{INTRODUÇÃO}

\begin{abstract}
Esta é a lei. Mas há alguma coisa que, se me fez ouvir o primeiro tiro com um alívio de segurança, no terceiro me deixa alerta, no quarto desassossegada, o quinto e o sexto me cobrem de vergonha, o sétimo e o oitavo eu ouço com o coração batendo de horror, no nono e no décimo minha boca está trêmula, no décimo primeiro digo em espanto o nome de Deus, no décimo segundo chamo o meu irmão. O décimo terceiro tiro me assassina - porquê eu sou o outro. (...) Essa justiça que vela o meu sono, eu a repudio, humilhada por precisar dela. Enquanto isso durmo e falsamente me salvo. Nós, os sonsos essenciais. ${ }^{1}$
\end{abstract}

Este artigo procura estabelecer uma discussão acerca de um tema de suma importância no cenário político, jurídico e social contemporâneo: o Direito Penal do Inimigo. Observamos que sempre foi e até hoje é dispensado um tratamento diferente àqueles considerados ora como estrangeiros, ora como estranhos, ora como inimigos, tratamento este

\footnotetext{
${ }^{1}$ LISPECTOR, Clarice. Mineirinho. In: Para não esquecer. São Paulo: Editora Ática, 1984.
} 
que consiste essencialmente na diminuição de garantias, sejam elas penais ou processuais penais, resultando em uma mitigação dos direitos fundamentais.

A relevância do tema emerge da necessidade atual de se repensar a sociedade e, conseqüentemente, o Direito, com suas raízes históricas e não-lineares, por um viés garantidor e humanitário. Devemos observar como estão e como estiveram sempre presentes na estrutura jurídico-normativa, muitas vezes de maneira pouco sutil, traços do que hoje se convencionou chamar de Direito Penal do Inimigo.

Desta forma, é importante fazer os seguintes questionamentos: é possível a existência de um Direito Penal do Inimigo em um Estado Democrático de Direito? Pode um sistema fundado em princípios garantidores dar um espaço legítimo - talvez possamos falar em um vácuo jurídico - em que não há garantias para determinadas pessoas, por serem essas mesmas pessoas consideradas inimigas? E quem são os inimigos? Como reconhecê-los? Os direitos dos cidadãos podem ser diminuídos para que os inimigos sejam identificados?

\section{O DIREITO PENAL DO INIMIGO}

Primeiramente, faz-se necessário traçar um panorama a respeito do principal teórico do chamado Direito Penal do Inimigo. Günther Jakobs, penalista alemão e professor aposentado da Cátedra de Direito Penal da Faculdade de Direito da Universidade de Bonn, na Alemanha, foi um dos principais interlocutores de Hanz Welzel, jurista que construiu e estruturou o sistema penal que hoje se denomina finalismo.

\subsection{O sistema penal finalista}

O sistema penal finalista, diferentemente daquele que o antecedeu - o sistema causalista $^{2}$ - introduziu na dogmática penal um conceito mais abrangente da conduta humana. Adota-se como tal a conduta que detém de forma inerente um para que, uma finalidade orientada na capacidade humana de agir racionalmente. Assim, os tipos penais foram complementados com uma característica especial que fazia da causação de um resultado naturalístico uma conduta humana: a finalidade.

\footnotetext{
${ }^{2}$ Nesse sistema, reduziu-se a conduta humana a uma relação de causa e efeito. O tipo objetivo nada mais era do que uma relação de causalidade. A ação era considerada um mero movimento corporal voluntário que possuía relação de causalidade com a modificação no mundo exterior, não analisando a vontade do agente. Essa teoria não foi capaz de diferenciar a conduta culposa da conduta dolosa, por deslocar os aspectos subjetivos (dolo e culpa) para a esfera da culpabilidade na Teoria do Delito.
} 
O desenvolvimento da teoria finalista da conduta é obra de Hanz Welzel, que deu ao tipo objetivo dos crimes dolosos uma face subjetiva ${ }^{3}$. Entretanto, não houve modificação no próprio tipo objetivo, que continuou a ser a relação de causalidade existente entre a ação e o fato ocorrido no mundo exterior. A ação, conforme sustentado pelos finalistas, é um acontecer não só causal, mas também final. A finalidade da conduta humana justifica-se pela capacidade que o homem possui de, graças ao seu saber causal e racional, prever, dentro de certos limites, as conseqüências possíveis de sua atividade, bem como direcionar a sua ação para a consecução de fins propostos.

Contudo, a intencionalidade prevista para a ação humana finalisticamente orientada também deve existir quando, em razão do objetivo, não se instituem fatores causais positivos, como nos casos dos crimes omissivos. Ou seja, devemos considerar como fato ou conduta própria a um sujeito objetivamente imputável todo resultado tipicamente estipulado, determinado e orientado de modo consciente e racional pelo agente, ou cuja evitação era previsível e, portanto, determinável.

Somente partindo do pressuposto da capacidade humana de prever racionalmente as consequiências de seus atos, poderia o Direito tratar o homem como sujeito responsável, cobrando-lhe uma postura ético-social em conformidade com a tábua de valores jurídicopenalmente desenhada na sociedade. Dessa forma, a missão do Direito Penal seria desvalorar as condutas que trouxessem em si a negação desta tábua ético-social de valores, desde que possível considerar o homem sujeito penalmente responsável por isso ${ }^{4}$. E apenas seria admissível desvalorar uma conduta humana pelo que traz em si de negativo, se a sua finalidade intrínseca fosse revelada.

A vontade, então, não pode ser separada de seu conteúdo, isto é, de sua finalidade, posto que toda conduta humana deve ser voluntária e toda vontade tem um fim. ${ }^{5} \mathrm{O}$ conceito de conduta humana finalista assume um caráter ontológico, pretendendo-se universal e livre de quaisquer juízos de valor, tais como licitude e ilicitude. E esse caráter universalizante da conduta humana pode ser entendido como a pedra de toque da definição da ação finalisticamente orientada como marco inicial para a análise do crime.

\section{$2.2 \mathrm{O}$ sistema penal funcionalista}

\footnotetext{
${ }^{3}$ GRECO, Luís. Um panorama da teoria da imputação objetiva. Rio de Janeiro: Editora Lúmen Juris, 2007. p. 08 .

${ }^{4}$ GUARAGNI, Fábio André. As teorias da conduta em direito penal: um estudo da conduta humana do précausalismo ao funcionalismo pós-finalista. São Paulo: Editora Revista dos Tribunais, 2005. p. 134 e ss.

${ }^{5}$ ZAFFARONI, Eugenio Raúl, PIERANGELI, José Henrique. Manual de direito penal brasileiro, volume 1: parte geral. $7^{a}$ Ed. São Paulo: Editora Revista dos Tribunais, 2008. p. 346.
} 
Os dois grandes nomes do funcionalismo penal são Claus Roxin e Günther Jakobs. Os dois penalistas alemães, todavia, possuem visões diferentes acerca do tema. Roxin propõe uma aproximação entre a dogmática e a política criminal. O sistema penal funcionalista por ele defendido, ao determinar a funcionalização das categorias do delito, não conduz ao arbítrio estatal por se pautar em valores e princípios constitucionais. Jakobs, no entanto, apóia-se em um sistema funcionalista sob um outro enfoque, conforme se verá a seguir.

\subsubsection{O sistema funcionalista de Günther Jakobs}

O funcionalismo sistêmico, defendido por Günther Jakobs, rejeita a idéia de ação encontrada primeiramente no sistema finalista e estabelece na estrutura jurídico-normativa penal a prevalência de necessidades regulativas do sistema. A finalidade precípua do Direito Penal, aqui, seria a manutenção e a garantia da identidade normativa da sociedade. Percebemos que a antiga concepção naturalista defendida pelos sistemas anteriores é superada por uma outra concepção - essencialmente normativista.

A manutenção de uma sociedade estável e duradoura, para Jakobs, está intimamente ligada à efetiva realização dos papéis sociais inerentes a cada cidadão. Com isso, podemos afirmar que a função do Direito seria a de possibilitar a seleção de determinadas expectativas de comportamento no contexto social - que no âmbito penal identificam-se como os imperativos e proibições - para que a estabilidade social almejada seja alcançada e, quando despedaçada, possa ser contrafaticamente sustentada. Jakobs, então, conceitua o Direito como uma "estrutura de um sistema social que se baseia na generalização congruente de expectativas comportamentais normativas" 6 .

O bem jurídico no sistema penal funcionalista de Jakobs é exatamente a norma penal. Diferentemente do que sustenta a Teoria do Delito clássica, isto é, o bem jurídico penal como algo a ser protegido em determinada sociedade, por caracterizar-se como um bem ou um interesse culturalmente cultivado e, conseqüentemente valorado, o funcionalismo defende, por meio da sanção penal, a proteção da própria norma penal. Há que se ressaltar, também, que o modelo funcionalista de Jakobs não se identifica com uma teoria da pena preventivista, nos moldes tradicionais. Isso significa que a pena não teria como função a prevenção da prática de

\footnotetext{
${ }^{6}$ REIS, Marco Antônio Santos. Novos rumos da dogmática jurídico-penal: da superação do finalismo e de sua suposta adoção pelo legislador brasileiro a um necessário esclarecimento funcionalista. In: Revista Brasileira de Ciências Criminais. Ano 17, nº 18. p. 61.
} 
delitos futuros, sob a ótica da teoria da prevenção geral positiva, mas essencialmente a prevenção de uma possível quebra da estrutura normativa da sociedade.

O modelo de Jakobs orienta-se, portanto, por uma concepção formal da sociedade, isto é, a sua organização normativa é compreendida a partir de si mesma, de sua configuração concreta. Surge no sistema penal funcional-sistêmico uma identidade normativa, que emana da compreensão geral dos membros da sociedade a respeito das regulações jurídicas, o que gera, assim, expectativas de condutas entre os mesmos.

Mas o que seria essa chamada identidade normativa? Jakobs pressupõe, ao partir de uma concepção formal da sociedade, que as normas ali vigentes são válidas e legítimas. Devido ao processo dialético de interação e comunicação existente entre os membros de uma determinada sociedade, consegue-se visualizar um grau mínimo de convergência valorativa, ou seja, podem ser ali identificados bens e valores comuns, oriundos da demanda social, que ele denominou de identidade normativa. Com isso, o penalista alemão descarta a possibilidade dessa interação social se fazer presente em uma sociedade totalitária, na qual as necessidades sociais são controladas (ou ignoradas) por um poder tirânico. Ou seja, somente é autorizado a se falar sobre identidades normativas em sociedades democráticas.

A eficácia normativa, então, é colocada em perigo quando não é observado o exercício (ou dever) de fidelidade ao direito e dessa não observância resulta o crime. No campo da culpabilidade funcional, a punibilidade irá orientar-se pela capacidade e possibilidade da produção de risco à eficácia normativa. Culpável é o ato, portanto, que nega a norma penal e é capaz de gerar a erosão da estrutura normativa que sustenta determinada sociedade.

No entanto, críticas ao funcionalismo sistêmico de Jakobs podem e devem ser feitas. Elencamos, aqui, algumas relativas aos seus aspectos essenciais:

a) o conceito sociológico de papel - que de forma indevida se imiscui na órbita do juridicamente relevante - reduz o fenômeno jurídico a sua faceta puramente sociológica; b) a manutenção da identidade normativa não nos parece fundamento suficiente para assegurar o respeito às garantias fundamentais. Com efeito, esse controle social dos papéis com vistas à estabilidade não pode ser mais importante do que a salvaguarda de um núcleo inatacável de dignidade humana; c) um sistema baseado em expectativas normativas, apesar de sua coerência interna, não possui concreção exata, sendo difícil enxergar a satisfação plena desses papéis esperados que, em regra, valem para um todo unitário. Um sistema assim estruturado ignora o caráter fragmentário que permeia todo um meio social em diferentes graus de intensidade; d) por fim, mas longe de esgotar o tema, se a concepção aqui esposada é correta, a concepção sistêmica conduz a uma intolerável instrumentalização do ente humano, reduzindo-o a um mero executor de papéis, isto é, a um meio para a consecução de uma discutível estabilidade. Tal postura é inadmissível para qualquer 
um que se proponha a discutir caminhos racionais para a contenção do poder punitivo. ${ }^{7}$

A pessoa, para Jakobs, é uma pessoa social. Ou seja, pessoa é quem possui a titularidade de direitos e a capacidade para assumir deveres dentro de uma sociedade normativamente organizada. $\mathrm{O}$ nexo comunicativo que serve de base à construção de uma identidade normativa só pode ser efetivo entre pessoas sociais, que cumprem os seus papéis sociais. A privação da característica de pessoa, apta a transformar um cidadão em inimigo se dá, em consonância com o sistema estabelecido por Jakobs, a partir do reconhecimento de que a qualidade da pessoa, isto é, a personalidade, não é em princípio algo dado pela natureza, mas sim uma atribuição normativa, quer seja de caráter moral, social e/ou jurídico.

O conceito de pessoa, para o penalista alemão, é diferente do conceito de ser humano: enquanto este é o resultado de processos naturais, aquele é um produto social que pode ser definido como uma unidade ideal de direitos e deveres que são administrados por meio de um corpo e de uma consciência. A definição de pessoa relaciona-se intrinsecamente com a capacidade do indivíduo de assimilar de forma vinculante a estrutura social e, conseqüentemente, o Direito. Dessa capacidade é extraído o reconhecimento social de um indivíduo como pessoa social, como cidadão. Para Jakobs, as crianças e os indivíduos que padecem de patologias psíquicas não possuem esse reconhecimento, essa capacidade de agir vinculada a um dever ou a uma obrigação, sendo excluídos do conceito de pessoa social. ${ }^{8}$

Diante desse raciocínio, retira-se o caráter de pessoa daqueles considerados como inimigos por não deterem a competência necessária para serem reconhecidos socialmente ao se distanciarem do Direito, sendo dispensável ao Estado tratá-los como pessoas.

Assim, percebemos no funcionalismo sistêmico de Jakobs uma excessiva preocupação com a preservação da eficácia normativa em detrimento da importância a ser dada às consequiências danosas do fato e até mesmo às circunstâncias pessoais do agente. $\mathrm{O}$ penalista alemão, ao defender a pessoalidade como construção exclusivamente normativa, sobrepõe ao conceito de pessoa o de sociedade, para que o bem jurídico penal - e conseqüentemente a (manutenção da) validade da norma - seja protegido.

\footnotetext{
${ }^{7}$ REIS, Marco Antônio Santos. Novos rumos da dogmática jurídico-penal: da superação do finalismo e de sua suposta adoção pelo legislador brasileiro a um necessário esclarecimento funcionalista. In: Revista Brasileira de Ciências Criminais. Ano 17, nº 18. p.62.

${ }^{8}$ MARTín. Luis Gracia. Sobre a negação da condição de pessoa como paradigma do "Direito Penal do Inimigo". In: Constituição e Processo: A resposta do constitucionalismo à banalização do terror. Cordenação de Marcelo Andrade Cattoni de Oliveira e Felipe Daniel Amorim Machado. Belo Horizonte: Del Rey, 2009. p. 348
} 


\subsection{O Direito Penal do Inimigo}

No prefácio da edição brasileira do livro "Direito Penal do Inimigo", Günther Jakobs conceitua o Direito Penal do Inimigo da seguinte forma:

São regras jurídicos-penais que, como suas correlatas, as regras do Direito Penal do Cidadão, somente são concebíveis enquanto tipos ideais. O Direito Penal do Inimigo é essencialmente, violência silenciosa; o Direito Penal do Cidadão é, sobretudo, comunicação sobre a vigência da norma. ${ }^{9}$

O bem jurídico para a doutrina penal tradicional é aquele bem ou interesse culturalmente cultivado e valorado em determinada comunidade jurídica. No sistema funcionalista-sistêmico de Jakobs, como já visto, o bem jurídico tutelado seria a própria norma penal e a função da pena seria a de confirmar a validade desta mesma norma. Deste modo, uma norma não é socialmente válida apenas quando é obedecida, mas também quando é sustentada contrafaticamente, pois em ambos os casos ela cumpre a função de obedecer à segurança das expectativas. ${ }^{10}$

Assim, uma ação contrária à norma penal causaria uma quebra da expectativa de comportamento esperado e, conseqüentemente, a pena teria como finalidade tanto marginalizar este ato defraudador de expectativas comunicativamente compartilhadas, quanto confirmar contrafaticamente a validade da norma penal violada, de forma a estabilizar, em primeiro plano, as expectativas e, mais adiante, o próprio sistema jurídico-social.

O inimigo, para Jakobs, seria um indivíduo que, por vontade própria, distanciou-se da estrutura normativa da sociedade, frustrando as expectativas sociais. Por outro lado, o cidadão é aquela pessoa titular de direitos e deveres, da qual se pode esperar o conhecimento das estruturas normativas e o comportamento segundo expectativas comunicativamente compartilhadas. O inimigo, portanto, deixaria de ser considerado como uma pessoa social cidadão - em função de seu comportamento, possível de ser compreendido como a vontade de abandonar a sociedade na qual se encontra e, assim, não mais ali compartilhar valor algum, tampouco respeitar suas condições de existência.

Günther Jakobs, ao discorrer sobre a dicotomia "Direito Penal do Inimigo x Direito Penal do Cidadão", elabora a seguinte tese:

\footnotetext{
${ }^{9}$ JAKOBS, Günther. Direito Penal do Inimigo. Org. Luiz Moreira, Eugênio Pacelli de Oliveira. Trad. Gercélia Batista de Oliveira Mendes. Rio de Janeiro: Ed. Lúmen Júris, 2008. p. XXV.

${ }^{10}$ JAKOBS, Günther. Direito Penal do Inimigo. Org. Luiz Moreira, Eugênio Pacelli de Oliveira. Trad. Gercélia Batista de Oliveira Mendes. Rio de Janeiro: Ed. Lúmen Júris, 2008. p. 33.
} 
Não se pode tratar de contrapor duas esferas isoladas do Direito Penal, mas de descrever dois pólos de um único mundo ou de mostrar duas tendências opostas de um único contexto do Direito Penal. Essas tendências podem muito bem se sobrepor, isto é, uma, a do tratamento do agente enquanto pessoa; e a outra, a do tratamento do agente como fonte de perigo ou como meio de intimidação de outros. 11

A partir disso, segundo Jakobs, poderia ser justificada a diminuição das proteções penais e processuais penais para os indivíduos que se distanciam da sociedade e não oferecem mais segurança cognitiva - os inimigos. O Direito Penal do Inimigo buscaria combater indivíduos cuja atitude evidencia um afastamento definitivo do Direito, não sendo possível esperar qualquer tipo de garantia cognitiva dos mesmos. ${ }^{12}$

O Direito Penal do Inimigo, então, trataria este indivíduo, que deliberadamente deixou de participar de uma sociedade comunicativamente construída, não como uma pessoa titular de direitos e deveres, mas como uma fonte de perigo que precisa ser eliminada para que a estrutura normativa e, conseqüentemente, a própria sociedade, não pereça. Percebe-se que o Direito Penal do Inimigo solapa um dos fundamentos de um Estado Democrático de Direito: a personalidade dos indivíduos.

Sobre esse ponto, Jakobs escreve:

Quem não pode oferecer segurança cognitiva suficiente de que se comportará como pessoa não só não pode esperar ainda ser tratado como pessoa, como tampouco o Estado está autorizado a tratá-lo ainda como pessoa, pois, de outro modo, estaria lesando o direito das outras pessoas à segurança. ${ }^{13}$

Uma forma de regular juridicamente a exclusão daqueles considerados inimigos seria a implementação e a conseqüente legitimação do Direito Penal do Inimigo. Aduz o penalista que, para que o Direito Penal excludente seja refreado, já que eliminá-lo seria tarefa impossível, é necessário, antes de tudo, reconhecer o Direito Penal do Inimigo e chamá-lo pelo nome.

De acordo com Jakobs, o Direito Penal do Inimigo otimizaria a proteção de bens jurídicos tradicionais e o Direito Penal do Cidadão, por sua vez, otimizaria a esfera de liberdade dos mesmos. O penalista alemão não acredita ser possível combater o terror com os meios de um Direito Penal de Estado de Direito, pois um Direito Penal que englobe tudo não seria capaz de conduzir de forma satisfatória esse combate, ao tratar seus inimigos como

\footnotetext{
${ }^{11}$ JAKOBS, Günther. Direito Penal do Inimigo. Org. Luiz Moreira, Eugênio Pacelli de Oliveira. Trad. Gercélia Batista de Oliveira Mendes. Rio de Janeiro: Ed. Lúmen Júris, 2008. p. 01.

${ }^{12}$ Seriam exemplos de possíveis inimigos nos tempos atuais: criminosos sexuais, econômicos e os integrantes da criminalidade organizada.

${ }^{13}$ JAKOBS, Günther. Direito Penal do Inimigo. Org. Luiz Moreira, Eugênio Pacelli de Oliveira. Trad. Gercélia Batista de Oliveira Mendes. Rio de Janeiro: Ed. Lúmen Júris, 2008. p. 17.
} 
pessoas e não como fonte de perigos. E arremata: "No Estado de Direito ideal na prática é diferente e isso (o direito penal do inimigo) lhe traz a oportunidade de não se desmantelar ao atacar seus inimigos." 14

Quais seriam, então, as características essenciais desse pólo ou dessa não tão nova tendência do Direito Penal? Podemos citar: a ampla antecipação da punibilidade, ou seja, desloca-se a atenção do fato ocorrido para o fato vindouro, como por exemplo os tipos de formação de organização criminosa ou terrorista e a falta de redução da pena proporcional à antecipação; transição da legislação penal para a legislação de combate; e a supressão de garantias processuais.

\subsubsection{Da antecipação da punibilidade}

Não há no Direito Penal do Inimigo espaço para que o Estado, a partir do exercício do poder punitivo, dialogue com os cidadãos por meio da imposição da pena e de seu caráter preventivo, seja ele geral, especial, positivo ou negativo. Há somente a necessidade de se combater perigos ou fontes de perigo. Essa violência silenciosa justificaria, por exemplo, a antecipação da punibilidade que se reflete na pena dirigida a fatos futuros - e não a atos já cometidos. Vislumbramos a representação desta característica do Direito Penal do Inimigo nos tipos em que a criminalização se dá a partir de condutas que acontecem no âmbito prévio à prática de qualquer delito, em que são punidos os chamados atos preparatórios. Tal situação encontra reflexos, por exemplo, nos casos de formação de organizações criminosas, podendo chegar até mesmo à punição para quem colabora ou faz apologia a tais organizações.

Luis Gracia Martin, citando Cancio Meliá, escreve a respeito dos tipos em que há antecipação da punibilidade que:

Esses tipos tomam como base os dados específicos de abandono permanente ao Direito e de constante ameaça aos princípios básicos da sociedade (falta de segurança cognitiva) e podem ser caracterizados porque seu objeto ainda não é a comissão de atos delitivos concretos e determinados, mas tão somente qualquer conduta informada e motivada pela pertença à organização que opera fora do Direito. $^{15}$

\footnotetext{
${ }^{14}$ Idem. p. 69.

15 MARTÍN. Luis Gracia. Sobre a negação da condição de pessoa como paradigma do "Direito Penal do Inimigo”. In: Constituição e Processo: A resposta do constitucionalismo à banalização do terror. Cordenação de Marcelo Andrade Cattoni de Oliveira e Felipe Daniel Amorim Machado. Belo Horizonte: Del Rey, 2009. p. 343.
} 
No âmbito do Direito Penal do Inimigo não é observada, tampouco, uma necessária proporcionalidade entre as penas de delitos nos quais há a antecipação da punibilidade e a daqueles que se configuram em função dos atos consumados e da efetiva lesão a determinado bem jurídico. Essa desproporcionalidade pode ser encontrada na relação existente entre a pena para atos preparatórios e a pena para atos consumados. $\mathrm{O}$ autor acima citado exemplifica tal situação ao afirmar que no Código Penal Espanhol a pena estabelecida para atos preparatórios de colaboração com bandos armados ou organizações terroristas é superior àquelas previstas para tentativa de homicídio e quase todos os tipos de lesões consumadas. ${ }^{16}$

\subsubsection{Da legislação de combate}

Jakobs reconhece vestígios do Direito Penal do Inimigo na legislação alemã ao serem utilizadas expressões como "leis de luta ou de combate”, fenômeno esse também recorrente no Brasil. O emprego de outras expressões tais como "guerra ao terror" ou "guerra ao narcotráfico" evidenciam a capacidade que o Direito Penal do Inimigo possui de adentrar de forma discreta aos olhos distraídos - no âmbito de um sistema jurídico que deve primar pela observância aos princípios penais e processuais penais garantidores, a fim de refrear o exercício abusivo do poder punitivo estatal.

A alusão à guerra ou ao combate nos remete a situações de exceção. Com ajuda dos recursos midiáticos, esses discursos provocam um sentimento de insegurança coletiva na sociedade e, conseqüentemente, a produção de inimigos. A partir disso, a idéia de segurança torna-se um dos principais fundamentos da guerra contra o terror e da promulgação de leis de combate a inimigos potenciais, sejam eles reais ou imaginários. E a busca incessante por essa segurança seria capaz de legitimar discursos que objetivam a inobservância a normas já constituídas por parte do aparato estatal e também de produzir novas regras sem o devido respeito aos princípios fundamentais consagrados constitucionalmente.

\subsubsection{Da supressão de garantias}

Outro símbolo inerente ao Direito Penal do Inimigo é a supressão de garantias, sejam elas penais ou processuais. Ao se considerar, a priori, sem o devido processo legal e

\footnotetext{
${ }^{16}$ MARTÍn. Luis Gracia. Sobre a negação da condição de pessoa como paradigma do "Direito Penal do Inimigo". In: Constituição e Processo: A resposta do constitucionalismo à banalização do terror. Cordenação de Marcelo Andrade Cattoni de Oliveira e Felipe Daniel Amorim Machado. Belo Horizonte: Del Rey, 2009. p. 344.
} 
amparado pelo princípio do contraditório e ampla defesa, um indivíduo culpado, ou melhor dizendo inimigo, é minado todo o arcabouço principiológico sobre o qual se constituiu o processo penal ao longo da história:

\begin{abstract}
O processo penal, por si só, não é garantia - nem à pessoa humana, nem à dignidade que lhe é inerente. Garantias são os princípios que o orientam e o informam, criações e construções culturais humanas tão suscetíveis à violação e ao autoritarismo, dentre elas, destacam-se o devido processo legal e o princípio do estado de inocência e de não-culpabilidade. (...) O estado de não-culpabilidade é a não aplicação da responsabilidade e da culpa aos indiciados ou aos acusados, antes de transitada em julgado a sentença penal condenatória. ${ }^{17}$
\end{abstract}

Jakobs concorda que o acusado é a pedra de toque do sistema processual em um Estado de Direito; é sujeito processual participante, característica essa que distingue o processo atual do processo inquisitório de épocas não tão remotas. No entanto, o penalista alemão acredita que elementos processuais de um Direito Penal do Inimigo, além de já estarem presentes no sistema atual ${ }^{18}$, são necessários para a proteção da sociedade contra seus inimigos. O Estado, para ele, abole direitos de forma juridicamente regulada - desde sempre.

\title{
2.3.4 Do retorno ao Estado de Polícia
}

Percebemos que no chamado Direito Penal do Inimigo há uma flexibilização dos direitos fundamentais, incompatível com um Estado Democrático de Direito. O Direito Penal deve se respaldar em um sistema de princípios e garantias capaz de limitar as pulsões de um Estado de Polícia. O Direito Penal do Inimigo, ao adentrar no âmbito do Direito Penal Garantista, dá o impulso necessário para a transição de um Direito Penal do fato, no qual a pena cumpre (ou deveria cumprir) todas as suas funções, para um Direito Penal do autor, que funciona como um direito de medidas de segurança, de eliminação de perigos.

Jakobs concorda que a tarefa de reprimir perigos iminentes é da polícia. No entanto, justifica a assunção dessa árdua tarefa pelo Direito Penal, apesar da possível policialização do Direito daí decorrente:

\footnotetext{
17 MARQUES, Daniela de Freitas. Sobre monitoramento eletrônico - Aquém da prisão cautelar, além da liberdade provisória. In: Constituição e Processo: A resposta do constitucionalismo à banalização do terror. Cordenação de Marcelo Andrade Cattoni de Oliveira e Felipe Daniel Amorim Machado. Belo Horizonte: Del Rey, 2009. p. 137.

18 Jakobs cita como exemplos, dentre outros, a prisão preventiva: tal medida não reconhece o culpado como pessoa, mas esgota-se em relação a ele na coação física. Ele sustenta que a forma dessa coação não se dirige a um indivíduo sujeito de direitos, mas contra um indivíduo que, com seus instintos e medos, torna-se perigoso para os trâmites jurídicos regulares, conduzindo-se como inimigo.
} 
A polícia não pode associar sanções asseguradoras de longo alcance ao fato da formação de uma organização terrorista - esse é o primeiro aspecto - e ela tampouco deve fazê-lo - esse é o segundo, porque há que se assegurar ao Direito Penal do Inimigo ao menos uma parte das garantias de Estado de Direito do Direito Penal material e do Direito Processual, não só para torná-lo sustentável para o Estado de Direito, como também para disfarçar a diferença em relação ao Direito Penal do Cidadão, que, nesse sentido, é totalmente comparável com as medidas de reabilitação e segurança repulsoras do perigo - nesse caso, especialmente a custódia de segurança - as quais, por seu lado, são institutos jurídicos de Direito Penal do Inimigo. ${ }^{19}$

Entendemos, diante das características aqui elencadas como integrantes do Direito Penal do Inimigo, que o Direito Penal especialmente dirigido contra os inimigos, para Jakobs, tem mais a tarefa de garantir segurança do que a de preservar a eficácia jurídica, e isso se revela na finalidade da pena e nos tipos penais correspondentes. Renunciar aos dispositivos do Direito Penal do Inimigo seria, para o penalista alemão, esvaziar o direito dos cidadãos à segurança. O Direito Penal transforma-se em repulsa de perigos.

\subsection{O Direito Penal do Inimigo como a terceira velocidade do Direito Penal}

O Direito Penal vive hoje um momento de transição, marcado por uma tendência expansionista. Tal tendência possui aspectos como a criação de novos bens jurídico-penais, a ampliação dos espaços de riscos jurídico-penalmente relevantes, a flexibilização das regras de imputação e a relativização dos princípios político-criminais garantidores. Percebemos, assim, a introdução de novos elementos ao Direito Penal tradicional, bem como a reinterpretação de suas garantias clássicas.

De acordo com o professor espanhol Jesús-Maria Silva Sanchez ${ }^{20}$, o Direito Penal moderno tem comportado três velocidades. A primeira velocidade é representada pelo Direito Penal que possui como sanção a pena privativa de liberdade. São mantidos os critérios clássicos de imputação, os princípios político-criminais e processuais, não sendo possível a flexibilização dos mesmos. Já a segunda velocidade diz respeito àqueles ilícitos em que a sanção imposta consiste em outras penas que não a de prisão, como as privativas de direitos ou pecuniárias, aplicadas principalmente aos delitos econômicos, o que produz uma flexibilização de garantias e estabelece novos elementos à ordem normativa, como a

\footnotetext{
${ }^{19}$ JAKOBS, Günther. Direito Penal do Inimigo. Org. Luiz Moreira, Eugênio Pacelli de Oliveira. Trad. Gercélia Batista de Oliveira Mendes. Rio de Janeiro: Ed. Lúmen Júris, 2008. p. 47

${ }^{20}$ SANCHEZ, Jesús-Maria Silva. A expansão do direito penal - aspectos da política criminal nas sociedades pós-industriais. Trad. Luiz Otávio Oliveira Rocha. In: As Ciências Criminais no Século XXI, v. 11. São Paulo: Editora Revista dos Tribunais, 2002.
} 
responsabilização objetiva e coletiva de dirigentes e a introdução da responsabilidade penal da pessoa jurídica.

A terceira velocidade, então, se for possível admiti-la, seria aquela na qual o Direito Penal da pena de prisão concorre com uma ampla flexibilização de garantias políticocriminais, de regras de imputação e de critérios processuais. A partir dessa análise e diante do exposto nos itens anteriores, podemos identificar o Direito Penal do Inimigo como parte integrante desta terceira velocidade da expansão do Direito Penal.

\section{UMA LINHA ABISSAL NO ESTADO DEMOCRÁTICO DE DIREITO}

\subsection{A teoria das linhas abissais de Boaventura de Sousa Santos}

A Teoria das Linhas Abissais de Boaventura de Sousa Santos é o complemento necessário às reflexões realizadas por ele em A Crítica da Razão Indolente ${ }^{21}$. Ali o professor sustenta que a modernidade foi erguida sobre dois pilares gêmeos: a regulação e a emancipação. Por meio dessas duas grandes promessas modernas é que se desenvolveram politica, economica e socialmente nossas sociedades - incluindo aí instituições como o Direito e as Artes. Seu argumento é o de que, num dado momento, esses pilares passaram a concorrer entre si, o que fez com que o pilar da regulação superasse o pilar da emancipação, tomando seu lugar. A conseqüência que daí advém é que nenhuma dessas duas grandes promessas pôde se realizar por completo ao longo da História: observou-se que não houve emancipação e tampouco regulação satisfatórias.

A complementação indispensável para o desenvolvimento da tese de Boaventura de Sousa Santos, veio em seu artigo Para além do Pensamento Abissal: Das linhas globais a uma ecologia de saberes ${ }^{22}$. Para entender o porquê e justificar a falta de emancipação e regulação satisfatórias ao longo do tempo, o sociólogo português sustenta, então, que o pensamento moderno é um pensamento formado por linhas abissais. As chamadas linhas abissais produzem distinções visíveis e invisíveis no campo da Ciência e do Direito, que dividem a realidade social em dois universos distintos: o lado de cá e o lado de lá da linha. A consequiência desta divisão é que o lado de lá se torna inconcebível como realidade para o

\footnotetext{
${ }^{21}$ SANTOS, Boaventura de Sousa. A crítica da razão indolente: contra o desperdício da experiência. In: Para um novo senso comum: A Ciência, o Direito e a Política na Transição Paradigmática. V. 1. São Paulo: Cortez Editora, 2001.

${ }^{22}$ SANTOS, Boaventura de Sousa. Para além do pensamento abissal: das linhas globais a uma ecologia de saberes. . In: Critical Review of Social Sciences, 78, October 2007: 3-46
} 
lado de cá da linha, sendo tomado como irrelevante e incompreensível na medida em que permanece externo, alheio ao conceito de outro e, conseqüentemente, inexistente.

Com isso, concebe-se que a competição paradigmática entre os pilares da modernidade (regulação/emancipação) só ocorre de fato naquilo que Boaventura chamou de o lado de cá da linha. Do lado de lá, todavia, vigoraria um outro paradigma: o da apropriação/violência. Lá não são realizadas as promessas da modernidade. As pessoas são sempre pensadas como objetos, jamais como sujeitos; não há conhecimento válido, não há critérios de legalidade. Isto é apropriação/violência.

No âmbito do Direito, do lado de cá da linha, temos o binômio legalidade/ilegalidade, que regula todo o sistema jurídico. Mas esse mesmo sistema jurídico constrói suas linhas abissais na medida em que ignora diversas existências que se tornam invisíveis, ininteligíveis e intraduzíveis por não pertencerem nem ao código legal nem ao ilegal. $^{23}$ Assim, de acordo com Boaventura, o legal e o ilegal são as duas únicas formas relevantes de existência perante a lei. Todas as demais manifestações de existência que não fazem parte deste código binário encontram-se do lado de lá da linha, onde a lógica da apropriação/violência se faz sempre presente.

No entanto, as linhas abissais produzidas entre e dentro das duas diferentes lógicas regulação/emancipação e apropriação/violência - estão em constante tensão e movimento. Argumenta-se que, durante o período em que as antigas colônias lutavam por sua independência, estavam também lutando contra a exclusão em decorrência do condicionamento ali imposto pelo paradigma da apropriação/violência. Conseqüentemente, estavam a reclamar o direito à inclusão no paradigma da regulação/emancipação. Todavia, a diminuição das linhas abissais - e da lógica da apropriação/violência - encontrou um obstáculo a partir de $1970^{24}$, quando surge, utilizando os termos desenvolvidos por Boaventura, um movimento de regresso ao colonial.

Tal movimento seria a resposta abissal ao que é percebido como uma intromissão ameaçadora do colonial nas sociedades metropolitanas. Este regresso assumiria três formas principais: o terrorista, o imigrante indocumentado e o refugiado. De modos distintos, cada um deles traz consigo a linha abissal global que define a exclusão radical e inexistência jurídica. Por exemplo, em muitas das suas disposições, a legislação anti-terrorista e de

\footnotetext{
${ }^{23}$ SANTOS, Boaventura de Sousa. Para além do pensamento abissal: das linhas globais a uma ecologia de saberes. . In: Critical Review of Social Sciences, 78, October 2007. p. 04.

${ }^{24}$ Importante ressaltar que obstáculos à superação da lógica da apropriação/violência sempre existiram ao longo da história, como, por exemplo, as atrocidades cometidas e supostamente justificadas durante as guerras.
} 
imigração segue a lógica reguladora do paradigma da apropriação/violência. ${ }^{25} \mathrm{O}$ território antigamente delimitado pelas linhas abissais, mais precisamente aquele onde predominava o código da regulação/emancipação, encontra-se hoje situado num território ambíguo, onde não se é capaz de, com precisão, determinar qual o paradigma dominante:

\begin{abstract}
$\mathrm{Na}$ sua perspectiva, a nova intromissão do colonial tem de ser confrontada com a lógica ordenadora da apropriação/violência. Chegou ao fim o tempo de uma divisão clara entre o Velho e o Novo Mundo, entre o metropolitano e o colonial. A linha tem de ser desenhada a uma distância tão curta quanto o necessário para garantir a segurança. O que costumava pertencer inequivocamente a este lado da linha é agora um território confuso atravessado por uma linha abissal sinuosa. O muro da segregação israelita na Palestina (Tribunal Internacional de Justiça, 2005) e a categoria de "combatente inimigo ilegal" (Dörmann, 2003; Harris, 2003; Kanstroom, 2003; Human Rights Watch, 2004; Gill e Sliedregt, 2005), criada pela administração dos EUA depois do 11 de Setembro, constituem possivelmente as metáforas mais adequadas da nova linha abissal e da cartografia confusa a que conduz. $^{26}$
\end{abstract}

Para o sociólogo português, a base militar americana em Guantánamo seria a representação da face mais grotesca do pensamento jurídico abissal, da criação, pelo lado de cá e dentro do mesmo, de um lado de lá como um não-território em termos jurídicos e políticos, um espaço impensável para o primado da lei, dos direitos humanos e da democracia.

3.2 O caráter abissal do Direito Penal do Inimigo e sua incompatibilidade com o Estado Democrático de Direito

Diante do exposto acima, é necessário delinear as características do Direito Penal do Inimigo que dão a ele um caráter abissal. Podemos entender que a estrutura simbólica do mundo ocidental foi construída a partir de duas idéias complementares: a de inimigos (apropriação/violência) e a de uniformidade normativa (regulação/emancipação). O que dá ao Direito Penal do Inimigo o caráter abissal e a sua conseqüente e inevitável incompatibilidade com o Estado Democrático de Direito?

Partindo-se da idéia de que o sujeito da imputação penal é homem, e não a pessoa social-normativa defendida por Jakobs, o sujeito das consequiências jurídico-penais também

\footnotetext{
${ }^{25}$ SANTOS, Boaventura de Sousa. Para além do pensamento abissal: das linhas globais a uma ecologia de saberes. . In: Critical Review of Social Sciences, 78, October 2007. p. 12.

${ }^{26}$ SANTOS, Boaventura de Sousa. Para além do pensamento abissal: das linhas globais a uma ecologia de saberes. . In: Critical Review of Social Sciences, 78, October 2007. p. 13.
} 
será o homem, ontologicamente analisado. O mal da pena, nos dizeres de Bernd Schünemann, não pode ser aplicado a um papel abstrato, mas a um homem real de carne e osso. ${ }^{27}$

Não podemos sustentar, então, que o Direito Penal possui como destinatário a pessoa no sentido de Jakobs. Devemos compreender o destinatário penal como o indivíduo, o homem real e empírico. O sujeito da imputação penal e da pena não deve ser uma pessoa entendida normativamente como uma construção social, mas sim o homem, o indivíduo humano. Schünemann ensina que "a substituição que propõe Jakobs do indivíduo pela pessoa como mero portador de um papel no Direito Penal destrói justamente a sua legitimação" ${ }^{28}$. Concordamos com Luis Gracia Martín no sentido de que, se o Direito se dirige nem às forças da natureza, nem aos animais, mas ao homem, a estrutura ontológica do ser humano deve ser o primeiro dado a ser levado em consideração. ${ }^{29}$

Assim, só é possível atribuir o caráter de Direito a uma estrutura normativa se a mesma respeitar o suporte central sobre o qual foi construído o sistema jurídico-penal: a concepção do homem como indivíduo responsável, protagonista de relações interpessoais. Recusar o homem responsável como o destinatário tanto da imputação penal quanto da pena, analisando-o por um viés apenas normativo, acaba por restringir o Direito a um sistema instável de força e de coerção.

A compatibilização do Direito Penal do Inimigo com o atual sistema jurídico, político e social não é sensata, tampouco prudente, pois a criação de inimigos fora de um contexto bélico dá asas para que devaneios autoritários possam se concretizar. A idéia de inimigo, então, pode ser entendida como um elemento conceitual contraditório dentro do Estado Democrático de Direito porque arrasta consigo a semente de sua destruição:

Por isso, a admissão jurídica do conceito de inimigo no direito (que não seja estritamente de guerra) sempre foi, lógica e historicamente, o germe ou o primeiro sintoma da destruição autoritária do Estado de direito, posto que se trata apenas de uma questão de quantidade - não de qualidade - de poder. O poder do soberano fica

\footnotetext{
${ }^{27}$ MARTÍN. Luis Gracia. Sobre a negação da condição de pessoa como paradigma do "Direito Penal do Inimigo”. In: Constituição e Processo: A resposta do constitucionalismo à banalização do terror. Cordenação de Marcelo Andrade Cattoni de Oliveira e Felipe Daniel Amorim Machado. Belo Horizonte: Del Rey, 2009. p.355.

${ }^{28}$ MARTÍN. Luis Gracia. Sobre a negação da condição de pessoa como paradigma do "Direito Penal do Inimigo”. In: Constituição e Processo: A resposta do constitucionalismo à banalização do terror. Cordenação de Marcelo Andrade Cattoni de Oliveira e Felipe Daniel Amorim Machado. Belo Horizonte: Del Rey, 2009. p. 357.

29 MARTÍN. Luis Gracia. Sobre a negação da condição de pessoa como paradigma do "Direito Penal do Inimigo”. In: Constituição e Processo: A resposta do constitucionalismo à banalização do terror. Cordenação de Marcelo Andrade Cattoni de Oliveira e Felipe Daniel Amorim Machado. Belo Horizonte: Del Rey, 2009. p. 357.
} 
aberto e incentivado a um crescente incremento a partir da aceitação da existência de um inimigo que não é pessoa. ${ }^{30}$

A identificação do inimigo como uma fonte de perigo que precisa ser eliminada leva a inevitável prática de um direito penal do autor há tempos contestado. Zaffaroni entende que o direito penal do autor nada mais é do que uma corrupção do próprio Direito Penal, pois o que se proíbe não é o ato em si, mas o ato como uma forma de ser do autor considerada delitiva:

\begin{abstract}
O direito penal que parte de uma concepção antropológica que considera o homem incapaz de autodeterminação (sem autonomia moral, isto é, sem capacidade para escolher entre o bem e o mal), só pode ser um direito penal de autor: o ato é sintoma de uma personalidade perigosa, que deve ser corrigida do mesmo modo que se conserta uma máquina que funciona mal. ${ }^{31}$
\end{abstract}

O perigo de abuso por parte do aparato estatal no combate ao inimigo é demasiado grande, pois não há uma definição clara acerca de quem é o inimigo e uma maneira segura de distingui-lo do cidadão, que seria o destinatário do Direito Penal tradicional. Ademais, a permissão para tratar aqueles cidadãos considerados a priori como inimigos, em desarmonia com pressupostos e princípios democráticos, coloca o Estado em posição similar a do inimigo que pretende combater. Podemos dizer, também, que seria difícil distinguir a guerra do Direito Penal do Inimigo, sendo aberto um espaço para a lógica de uma guerra interna e eterna, fundamentada na necessidade de se buscar uma suposta segurança nacional. Há que se ter em mente que a teoria social do direito penal proposta por Günther Jakobs evoca uma funcionalização sistêmica da sociedade, em prejuízo da humanidade que dignifica o ser no mundo. ${ }^{32}$

A limitação do Direito, conforme dito em parágrafos anteriores, a um sistema instável de força e coerção autoriza o surgimento de um espaço para o paradigma da apropriação/violência dentro do próprio Direito, usando os termos utilizados por Boaventura de Sousa Santos, capaz de criar uma linha abissal no âmbito do sistema penal e processual penal informado por princípios garantidores. A antecipação da punibilidade, a legislação de combate, a supressão de garantias e o retorno ao estado de polícia nada mais são do que a

\footnotetext{
${ }^{30}$ ZAFFARONI, Eugenio Raúl. O inimigo no direito penal. Trad. Sérgio Lamarão. Rio de Janeiro: Ed. Revan, 2007. p. 153.

31 ZAFFARONI, Eugenio Raúl, PIERANGELI, José Henrique. Manual de direito penal brasileiro, volume 1: parte geral. $7^{a}$ Ed. São Paulo: Editora Revista dos Tribunais, 2008. p. 107.

32 JAKOBS, Günther. Tratado de direito penal: teoria do injusto penal e culpabilidade. Coordenador e supervisor: Luiz Moreira. Trad. Gercélia Batista de Oliveira Mendes e Geraldo de Carvalho. Belo Horizonte: Del Rey, 2008. p. viii.
} 
lógica da apropriação/violência a contaminar a lógica da regulação/emancipação. A consequiência disso é a concepção do vírus letal ao Estado Democrático de Direito, dentro e sob os cuidados do próprio Direito.

\section{AS TÁTICAS DE CONTENÇÃO AO DIREITO PENAL DO INIMIGO}

\subsection{A proposta estática de Günther Jakobs}

A tática de contenção estática ao Direito Penal do Inimigo, proposta por Günther Jakobs, paradoxalmente, é o próprio Direito Penal do Inimigo. A princípio soa contraditório afirmar que a tática de contenção é exatamente o objeto dessa mesma contenção. No entanto, conforme veremos a seguir, só mediante o estabelecimento de um tratamento diferenciado aos inimigos poderá, para o penalista alemão, ser refreado o avanço dessa tendência que ameaça todo o Direito Penal.

A utilização legítima do Direito Penal do Inimigo partiria de uma autorização proveniente do Direito Penal como meio de diferenciar o tratamento punitivo dado aos cidadãos - pessoas sociais - e aos inimigos. Dessa maneira, o Direito Penal do Inimigo estaria restrito a um âmbito de incidência estanque, sendo que fora desse espaço continuaria a valer os princípios do direito penal liberal ${ }^{33}$. Assim, seria permitido que ambos - o Direito Penal do Inimigo e o Direito Penal do Cidadão - convivessem dentro dos limites de um Estado Democrático de Direito, o que, conforme sustenta Zaffaroni "não se alteraria uma tradição pacífica na doutrina penal, que sempre o admitiu sem reparar na contradição que comporta". 34

Ao se permitir um espaço legítimo para o inimigo dentro do Direito e fora de um contexto bélico, Jakobs planta a semente necessária para que o Estado Absoluto - no qual não são tolerados limites para a contenção do poder punitivo - passe a crescer. O Direito Penal do Inimigo limitaria a efetivação dos princípios do Estado de Direito ao andar de mãos dadas com medidas emergenciais fundadas na idéia de necessidade. E, conforme o entendimento de Giorgio Agamben, a necessidade não conhece lei nem limites ao ser invocada como fundamento do estado de exceção:

\footnotetext{
${ }^{33}$ ZAFFARONI, Eugenio Raúl. O inimigo no direito penal. Trad. Sérgio Lamarão. Rio de Janeiro: Ed. Revan, 2007. p. 156.

${ }^{34}$ ZAFFARONI, Eugenio Raúl. O inimigo no direito penal. Trad. Sérgio Lamarão. Rio de Janeiro: Ed. Revan, 2007. p.159.
} 
Uma opinião recorrente coloca como fundamento do estado de exceção o conceito de necessidade. Segundo o adágio latino muito repetido (uma história da função estratégica dos adágia na literatura jurídica ainda está por ser escrita), necessitas legem non habet, ou seja, a necessidade não tem lei, o que deve ser entendido em dois sentidos opostos: 'a necessidade não reconhece nenhuma lei' e 'a necessidade cria sua própria lei’ (nécessité fait loi). ${ }^{35}$

Mas quem é capaz de julgar o que é a necessidade? Somente aqueles que detêm o poder. Assim, a suspensão do Estado de Direito fica adstrita a um arbítrio que designará como inimigo aquele que considerar oportuno à época. Não há mecanismos seguros para identificar quem é o inimigo, na medida em que não existe um conceito preciso do mesmo. Conforme dito em itens anteriores, a imposição do rótulo de inimigo sempre foi dependente e intrinsecamente ligada àqueles que detêm o poder.

Diante disso, não é possível aceitar a proposta estática de contenção do Direito Penal do Inimigo defendida por Jakobs. Ao serem legitimados espaços governados pelo paradigma da apropriação/violência dentro do modelo ideal de Estado de Direito que deve ser orientado pelo binômio da regulação/emancipação, está também permitindo ao detentor do poder estabelecer o que é a necessidade a ser invocada para a utilização do Direito Penal do Inimigo. Esse arbítrio da necessidade retira a utilidade do modelo ideal, que deixa de orientar as ações para a contenção do avanço do Estado de Polícia.

\subsection{A proposta dinâmica de Eugenio Raúl Zaffaroni}

Zaffaroni encontra um erro tático na proposta de contenção do Direito Penal do Inimigo estabelecida por Jakobs. O penalista alemão, ao fundamentar suas idéias a partir de um modelo sistêmico, não consegue perceber a dinamicidade de estruturas que estão em constante interação e transformação. Com isso, não é possível enxergar, por meio do sistema por ele determinado, a dialética existente entre o Estado de Direito e o poder punitivo.

A partir da idéia já exposta de que os Estados de Direito não são nada além da contenção dos Estados de Polícia, penosamente conseguidos como resultado da experiência acumulada ao longo das lutas contra o poder absoluto, Zaffaroni defende a importância do modelo ideal de Estado de Direito como forma de contenção do Direito Penal do Inimigo. O Estado de Polícia sempre esteve vivo e pulsante dentro do Estado de Direito e, por isso, impossível a concretização fática do modelo ideal. No entanto, não é pela ausência de realização deste modelo ideal que o mesmo não deve ser utilizado como elemento orientador

\footnotetext{
${ }^{35}$ AGAMBEN, Giorgio. Estado de Exceção.Trad. Irari D. Poleti. São Paulo: Boitempo, 2004. p. 40.
} 
para o aperfeiçoamento do Estado Democrático de Direito, apontando os defeitos que a realidade nos apresenta.

O que se propõe é atenuar as pulsões do Estado de Polícia, de forma a permitir apenas a passagem de um poder punitivo menos irracional, ao construir uma barreira intransponível para o de maior irracionalidade, pois:

Existe uma dialética contínua no Estado de direito real, concreto ou histórico, entre este e o Estado de polícia. O Estado de polícia que o Estado de direito carrega em seu interior nunca cessa de pulsar, procurando furar e romper os muros que o Estado de direito lhe coloca. ${ }^{36}$

A perspectiva dinâmica de contenção do Direito Penal do Inimigo é sustentada pela constatação de que é impossível manter o Estado de Polícia limitado a um compartimento estanque e isolado dentro do Estado de Direito, já que é da sua natureza a tentativa incansável de instaurar a prevalência de uma vontade arbitrária sobre as demais. Impossível acreditar que o Direito Penal do Inimigo se contentaria com um espaço reduzido para o exercício do seu poder. O verdadeiro inimigo do Direito Penal e, conseqüentemente, do Estado Democrático de Direito é o próprio Estado de Polícia.

Assim, a perspectiva de contenção dinâmica defendida por Zaffaroni tem como função constatar para resistir, diferentemente da proposta estática de Jakobs, que pugna pela constatação para legitimar ou até mesmo pela omissão como forma de ocultação dos vestígios do Estado de Polícia. Não se pode permitir a legitimação das práticas que maculam o modelo ideal a ser alcançado.

O Direito Penal, ao autorizar ou tolerar a introdução do inimigo, com o nome que for, no sistema jurídico, cultivou em seu interior as sementes de um Estado Absoluto. Não podemos renunciar, portanto, ao exemplo ideal de Estado de Direito como mote orientador, pois é na comparação entre esses dois Estados que se faz possível a construção de um modelo no qual o Estado de Polícia não tenha espaço para prevalecer:

\footnotetext{
Os defeitos dos Estados de direito reais ou históricos surgem por comparação com o princípio ou ideal e o direito penal deve tentar a sua superação aproximando-se deste modelo. A presença do hostis nunca pode ser legitimada sem que se abra mão do princípio do Estado de Direito; em outras palavras, caso se pretenda manter esse princípio, deve-se, necessariamente, rechaçar a presença do hostis. O Estado de polícia, por sua vez, não poupará esforço algum para estabelecê-la e restabelecê-la; o direito penal do Estado de direito não tem alternativa senão lutar para suprimi-la. ${ }^{37}$
}

\footnotetext{
${ }^{36}$ ZAFFARONI, Eugenio Raúl. O inimigo no direito penal. Trad. Sérgio Lamarão. Rio de Janeiro: Ed. Revan, 2007. p. 170.

${ }^{37}$ ZAFFARONI, Eugenio Raúl. O inimigo no direito penal. Trad. Sérgio Lamarão. Rio de Janeiro: Ed. Revan, 2007.. p. 191.
} 
Diante da criação de estados de emergência permanentes no âmbito do Estado Democrático de Direito, o que se espera do Direito Penal - que hoje se encontra perdido e a voar em círculos - é a observância e o respeito aos princípios informadores do sistema e, depois de constatados os defeitos que distanciam o modelo real do ideal, exercer ao máximo o poder jurídico de contenção para reduzi-los e, quiçá num futuro, eliminá-los.

\section{CONSIDERAÇÕES FINAIS}

Diante de todo o exposto ao longo deste trabalho, vislumbramos, como conseqüência de uma possível inserção considerada legítima do Direito Penal do Inimigo em um Estado de Direito, a idéia - talvez ingênua - de incumbir ao Direito Penal a tarefa de compatibilizar o incompatível. Tarefa essa que, se levada até as últimas consequiências, poderá solapar o arcabouço do Estado Democrático de Direito, fundado nos direitos fundamentais historicamente conquistados.

Por meio da criação de inimigos, os elementos fundadores e justificadores de discursos como o de Segurança Nacional e Lei e Ordem passam a se incorporar no cotidiano de toda a sociedade. Para que sejam determinados os temidos inimigos, impossíveis de serem reconhecidos a priori, é necessária a mitigação de direitos fundamentais - ardua e historicamente conquistados - não só dos inimigos, mas de todo e qualquer cidadão.

E, mesmo que fosse possível distinguir os inimigos dos cidadãos, não seria lícito dispensar um tratamento diferenciado aos primeiros, que diminuísse as suas garantias penais e processuais penais. Ainda que o inimigo possa existir do ponto de vista fático, não poderíamos tratá-lo como inimigo do ponto de vista normativo. O inimigo não é um outro alheio, um outro absoluto e distante dos demais. Como na introdução deste trabalho, o décimo terceiro tiro nos assassina. Porque nós também somos o outro.

Podemos dizer que o projeto da modernidade conduz à institucionalização da produção de inimigos ${ }^{38}$; ademais, é preciso admitir que os problemas e paradoxos que a modernidade produz não são passíveis de serem solucionados pelo Direito Penal, que recebeu o papel da marionete de um louco que se comporta como o da passagem abaixo:

Perguntaram a um louco que havia perdido a sua chave na floresta, por que estava procurando sob a luz do poste da rua, no que ele respondeu: aqui tem mais luz.

\footnotetext{
${ }^{38}$ JAKOBS, Günther. Direito Penal do Inimigo. Org. Luiz Moreira, Eugênio Pacelli de Oliveira. Trad. Gercélia Batista de Oliveira Mendes. Rio de Janeiro: Ed. Lúmen Júris, 2008. p. xv.
} 
Procurar flexibilizar as garantias constitucionais na perspectiva de resolver os

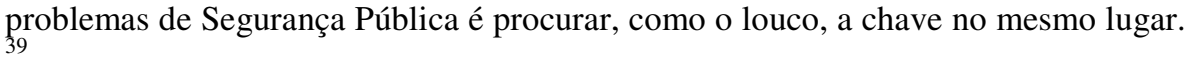

Da mesma maneira que o estado de exceção apresenta-se como a forma legal daquilo que não pode ter forma legal ${ }^{40}$, o Direito Penal do Inimigo quer pretender-se Direito, não sendo Direito. Não negamos a existência recorrente de práticas ao longo da História que podem ser identificadas como integrantes desse sistema diferenciador de inimigos e pessoas. No entanto, admitir a existência - e a partir daí tentar buscar soluções para que o direito penal real se aproxime do ideal - não é o mesmo que construir discursos que legitimem ou justifiquem tais práticas.

Há que se destacar, ainda, que a identificação dos inimigos sempre esteve intimamente ligada àqueles que detém o poder. Essa situação conduz ao arbítrio característico de um Estado de Polícia, que o Estado Democrático de Direito deve se empenhar em combater:

\begin{abstract}
Pode-se afirmar que em todas as épocas, com maior ou menor crueldade - segundo as condições e circunstâncias - a tendência tenha sido a de uma repressão penal plural, de acordo com a qual os autores de delitos graves (patibulários) e os dissidentes foram eliminados, os marginais ou indesejáveis foram neutralizados e, finalmente, os ocasionais foram tratados como pessoas semelhantes àquelas que detinham o poder ou a seus aliados: assim, teriam cometido erros passageiros, merecendo uma certa benevolência nos poucos e raros casos em que eram submetidas ao poder punitivo. ${ }^{41}$
\end{abstract}

O incremento da criminalidade nos últimos anos teve como conseqüência uma forte demanda por políticas criminais mais rígidas, exigindo-se do Estado respostas criminalizadoras e penalizadoras satisfatórias e eficientes. Está em voga nos meios de comunicação a utilização de expressões como guerra contra o terror ou também luta contra a criminalidade. Devemos ter em vista, no entanto, que a criminalidade é um problema $d a$ comunidade, que nasce na comunidade e que deve ser solucionado (ou ao menos tentar ser solucionado) pela comunidade. O problema criminal possui diversas raízes e acreditar que a resposta e a solução para o mesmo deve necessariamente ser encontrada no âmbito legislativo-penal é uma ilusão. A criação de leis mais rígidas nada mais é do que uma panacéia; a promulgação de tais leis não possui o condão de diminuir a prática delitiva.

\footnotetext{
${ }^{39}$ ROSA, Alexandre de Morais da. Garantias Constitucionais: um discurso que não seduz.. In: Constituição e Processo: A resposta do constitucionalismo à banalização do terror. Cordenação de Marcelo Andrade Cattoni de Oliveira e Felipe Daniel Amorim Machado. Belo Horizonte: Del Rey, 2009. p. 27.

${ }^{40}$ AGAMBEN, Giorgio. Estado de exceção.Trad. Irari D. Poleti. São Paulo: Boitempo, 2004. p. 12.

${ }^{41}$ ZAFFARONI, Eugenio Raúl. O inimigo no direito penal. Trad. Sérgio Lamarão. Rio de Janeiro: Ed. Revan, 2007. p. 36.
} 
A questão criminal é muito mais complexa do que aquilo que nos querem fazer acreditar os discursos muitas vezes reacionários e supressores de garantias tão recorrentes na mídia. Podemos entender o crime como um fenômeno inerente a todo e qualquer agrupamento social e o que nos resta é somente uma tentativa de controle razoável - e não de eliminação do crime. A criminalidade continuará sendo um enigma, quiçá impossível de solução.

O que observamos com o avanço de medidas características do Direito Penal do Inimigo é o tríplice ocaso do direito penal e processual penal: o ocaso das garantias formais, o ocaso das garantias materiais e ocaso do princípio da utilidade da intervenção penal. ${ }^{42}$ São inumeráveis os preceitos penais das novas legislações que utilizam cláusulas gerais vagas, de modo a imprecisar a conduta típica, conduzindo à supressão da garantia de liberdade do cidadão frente ao poder punitivo do Estado. As garantias materiais do Direito Penal e Processual Penal, tais como a proporcionalidade, a culpabilidade, a presunção de inocência e o devido processo legal, também são mitigadas por essa demasiada vontade punitiva. Observamos que há por toda parte um intervencionismo penal cada vez mais intenso e abrangente que não resulta na diminuição da criminalidade.

O Estado de Polícia tem conseguido derrubar algumas barreiras do Estado Democrático de Direito. E outras ainda serão destruídas, aproximando cada vez mais o paradigma da apropriação/violência do paradigma da regulação/emancipação. As linhas abissais previstas por Boaventura de Sousa Santos continuam a ser traçadas.

No entanto, é necessária a cada derrubada, a cada desenhar de novas linhas, a construção de uma outra barreira ainda mais sólida e consistente. E se chegar o dramático dia em que todas as barreiras limitadoras do Estado de Polícia caírem, não "seria lícito ao direito penal abandonar a essência do seu discurso de resistência, pois cedo ou tarde o Estado de direito renascerá." 43

Acreditamos, portanto, que é exatamente onde são apresentadas falhas (históricas e normativas) que devemos cuidar de preservar a intangibilidade do modelo ideal, instrumento necessário para o aperfeiçoamento do Estado Democrático de Direito almejado.

\section{REFERÊNCIAS BIBLIOGRÁFICAS}

AGAMBEN, Giorgio. Estado de exceção. Trad. Irari D. Poleti. São Paulo: Boitempo, 2004.

\footnotetext{
${ }^{42}$ ZAFFARONI, Eugenio Raúl, PIERANGELI, José Henrique. Manual de direito penal brasileiro, volume 1: parte geral. São Paulo: Editora Revista dos Tribunais, 2008. p. 15.

${ }^{43}$ ZAFFARONI, Eugenio Raúl. O inimigo no Direito Penal. Trad. Sérgio Lamarão. Rio de Janeiro: Ed. Revan, 2007. p. 177.
} 
FERRAJOLI, Luigi. Direito e razão: teoria do garantismo penal. São Paulo: Editora Revista dos Tribunais, 2002.

GRECO, Luís. Um panorama da teoria da imputação objetiva. Rio de Janeiro: Editora Lúmen Juris, 2007.

GUARAGNI, Fábio André. As teorias da conduta em direito penal: um estudo da conduta humana do pré-causalismo ao funcionalismo pós-finalista. São Paulo: Editora Revista dos Tribunais, 2005.

HASSEMER, Winfried. Direito Penal Libertário. Trad. Regina Greve. Belo Horizonte: Del Rey, 2007.

JAKOBS, Günther. Direito Penal do Inimigo. Org. Luiz Moreira, Eugênio Pacelli de Oliveira. Trad. Gercélia Batista de Oliveira Mendes. Rio de Janeiro: Ed. Lúmen Júris, 2008.

Norm, Person, Gesellschaft. Vorüberlegungen zu einer Rechtsphilosophie. In: Wissenchaftliche Abhandlungen und Reden zur Philosophie, Politik und Geistesgeschichte. Band 23. Dunker \& Humblot - Berlin.

. Tratado de direito penal: teoria do injusto penal e culpabilidade. Coordenador e supervisor: Luiz Moreira. Trad. Gercélia Batista de Oliveira Mendes e Geraldo de Carvalho. Belo Horizonte: Del Rey, 2008.

JAKOBS, Günther e MELIÁ, Manuel Cancio. Direito Penal do Inimigo: noções e críticas. Org. e trad. André Luís Callegari, Nereu José Giacomolli. $3^{\text {a }}$ Ed. -Porto Alegre: Livraria do Advogado Ed., 2008.

LISPECTOR, Clarice. Para não esquecer. São Paulo: Editora Ática, 1984.

MARQUES, Daniela de Freitas. Sobre monitoramento eletrônico - Aquém da prisão cautelar, além da liberdade provisória. In: Constituição e Processo: A resposta do constitucionalismo à banalização do terror. Cordenação de Marcelo Andrade Cattoni de Oliveira e Felipe Daniel Amorim Machado. Belo Horizonte: Del Rey, 2009

MARTÍN. Luis Gracia. Sobre a negação da condição de pessoa como paradigma do "Direito Penal do Inimigo". In: Constituição e Processo: A resposta do constitucionalismo à banalização do terror. Cordenação de Marcelo Andrade Cattoni de Oliveira e Felipe Daniel Amorim Machado. Belo Horizonte: Del Rey, 2009

MORGET, Geralide Louisa. Feindstrafrecht: Eine Kritische Analyse. Duncker \& Humblot Berlin.

REIS, Marco Antônio Santos. Novos rumos da dogmática jurídico-penal: da superação do finalismo e de sua suposta adoção pelo legislador brasileiro a um necessário esclarecimento funcionalista. In: Revista Brasileira de Ciências Criminais. Ano 17, nº 18, maio - junho 2009. 
ROSA, Alexandre de Morais da. Garantias Constitucionais: um discurso que não seduz.. In: Constituição e Processo: A resposta do constitucionalismo à banalização do terror. Cordenação de Marcelo Andrade Cattoni de Oliveira e Felipe Daniel Amorim Machado. Belo Horizonte: Del Rey, 2009.

SANCHEZ, Jesús-Maria Silva. A expansão do direito penal - aspectos da política criminal nas sociedades pós-industriais. Trad. Luiz Otávio Oliveira Rocha. In: As Ciências Criminais no Século XXI, v. 11). São Paulo: Editora Revista dos Tribunais, 2002.

SANTOS, Boaventura de Sousa. A crítica da razão indolente: contra o desperdício da experiência. In: Para um novo senso comum: A Ciência, o Direito e a Política na Transição Paradigmática. V. 1. São Paulo: Cortez Editora, 2001.

Para além do pensamento abissal: das linhas globais a uma ecologia de saberes. . In: Critical Review of Social Sciences, 78, October 2007: 3-46.

WACQUANT, Löic. As prisões da miséria. Trad. André Telles. Rio de Janeiro: Jorge Zahar Ed., 2001.

ZAFFARONI, Eugenio Raúl. $O$ inimigo no direito penal. Trad. Sérgio Lamarão. Rio de Janeiro: Ed. Revan, 2007.

ZAFFARONI, Eugenio Raúl, PIERANGELI, José Henrique. Manual de direito penal brasileiro. Volume 1: parte geral. $7^{\text {a }}$ Ed. São Paulo: Editora Revista dos Tribunais, 2008. 